\title{
CHARACTERIZATION OF A TRANSIENT + 2 SULFUR OXIDATION STATE INTERMEDIATE FROM THE OXIDATION OF AQUEOUS SULFIDE
}

\author{
Murthy A. Vairavamurthy and Weiqing Zhou \\ Geochemistry Program \\ Applied Physical Sciences Division \\ Department of Applied Science \\ Brookhaven National Laboratory \\ Upton, New York 11973
}

Submitted to an ACS Symposium Series Volume

GEOCHEMICAL TRANSFORMATIONS OF SEDIMENTARY SULFUR

(in press)

April 1995

By acceptance of this article, the publisher and/or recipient acknowledges the U.S. Government's right to retain a nonexclusive, royalty-free licence in and to any copyright covering this paper.

This research was performed under the auspices of the U.S. Department of Energy Division of Engineering and Geosciences of the Office of the Basic Energy Sciences (Brookhaven National Laboratory Contract No. DE-AC02-76CH00016). 


\section{DISCLAIMER}

Portions of this document may be illegible in electronic image products. Images are produced from the best available original document. 


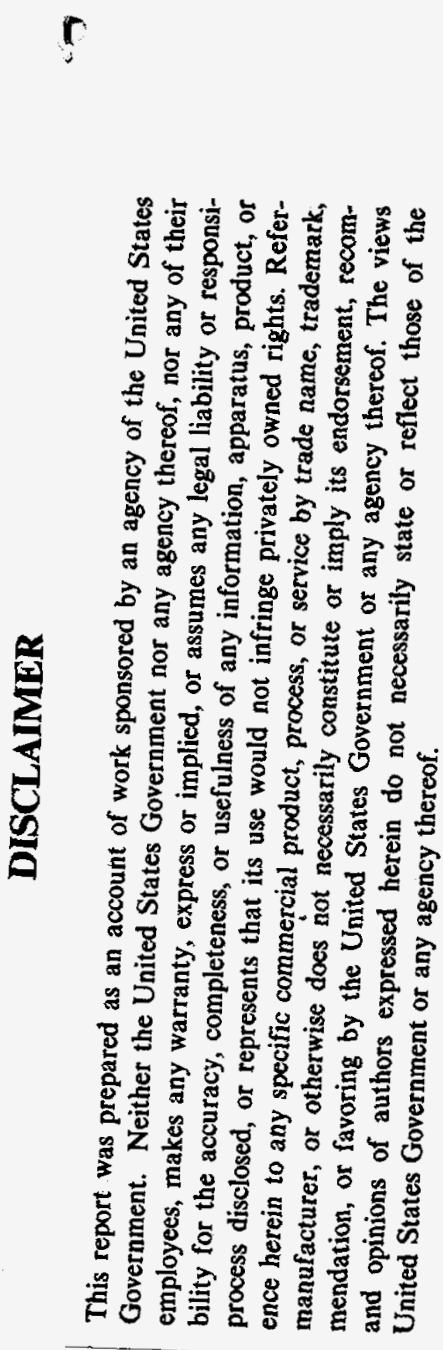

\title{
Characterization of a Transient +2 Sulfur Oxidation State Intermediate from the Oxidation of Aqueous Sulfide
}

\author{
Murthy A. Vairavamurthy and Weiqing Zhou \\ Geochemistry Program \\ Applied Physical Sciences Division \\ Department of Applied Science \\ Brookhaven National Laboratory \\ Upton, New York 11973
}

\begin{abstract}
The oxidation of $\mathrm{H}_{2} \mathrm{~S}$ to sulfate involves a net transfer of eight electrons, and occurs through the formation of several partially oxidized intermediates with oxidation states ranging from -1 to +5 . The known intermediates include elemental sulfur (oxidation state 0 ), polysulfides (outer sulfur: -1 , inner sulfur: 0 ), sulfite $(+4)$ and thiosulfate (outer sulfur: -1 , inner sulfur: +5 ). A noticeable gap in this series of intermediates is that of a +2 sulfur oxidation state oxoacid/oxoanion species, which was never detected experimentally. Here, we present evidence for the transient existence of a +2 oxidation state intermediate in the $\mathrm{Ni}(\mathrm{II})$-catalyzed oxidation of aqueous sulfide. X-ray absorption near-edge structure (XANES) spectroscopy and Fourier-transform-infrared (FT-IR) spectroscopy were used to characterize this species; they suggest that it has a sulfoxylate ion $\left(\mathrm{SO}_{2}^{2-}\right)$ structure.
\end{abstract}

The biogeochemical sulfur cycle is extremely complex because this element can exist in several oxidation states between -2 and +6 , and it forms a large variety of inorganic and organic compounds. Hydrogen sulfide and the sulfate ion, the commonest inorganic sulfur species which play important roles in the atmospheric, aquatic, and sedimentary transforma-tions of sulfur, contain sulfur atoms in the highly reduced $(-2)$ and the highly oxidized $(+6)$ oxidation states, respectively. In anoxic marine environments, hydrogen sulfide is formed mainly by the bacterial reduction of sulfate (l). The formation of hydrogen sulfide in hydrothermal systems probably occurs by a thermochemical reduction mechanism (2), although hightemperature bacterial reduction also is possible (3). Oxidation converts $\mathrm{H}_{2} \mathrm{~S}$ back to sulfate, but also forms several partially oxidized intermediates such as polysulfides, elemental sulfur, sulfite, and thiosulfate (4-10). Several of these intermediates (for example, polysulfides, thiosulfate) play major roles in a number of important biogeachemical processes, such as pyrite formation (1I), sulfur incorporation into 
organic matter $(12,13)$, cycling of metal elements (14), and bacterial energetics $(15)$. In natural waters, dissolved oxygen usually is the principal oxidant although redox transformations of some metals and nonmetals are frequently coupled to the oxidation of sulfide (16). In addition to chemical oxidation, bacteria also play an important role in sulfide oxidation which is carried out in conjunction with their energy metabolism (17).

The oxidation of $\mathrm{H}_{2} \mathrm{~S}$ to $\mathrm{SO}_{4}{ }^{2-}$ involves an overall transfer of eight electrons. The formation of several intermediates with oxidation states in between those of the end members (elemental sulfur: oxidation state 0 ; polysulfides: outer sulfur, -1 , inner sulfur, 0 ; sulfite: +4 ; thiosulfate: outer sulfur, -1 , inner sulfur, $+5(15)$ ) suggests that oxidation proceeds through a series of step-wise electron-transfer reactions. A noticeable gap is that of a +2 sulfur oxidation state oxoacid/oxoanion species, which was never detected experimentally. In fact, there has been no clear experimental evidence for its existence under any circumstance, although the occurrence of species with stoichiometry $\mathrm{H}_{2} \mathrm{SO}_{2}$ (18-20) and $\mathrm{HSO}_{2}^{-}(7)$ was proposed. According to Schmidt (1972), the oxoacid $\mathrm{H}_{2} \mathrm{SO}_{2}$ (and its corresponding oxoanion), "... at best may be regarded as a postulated intermediate in some complicated reactions of sulfur chemistry" (21). In this paper, we present evidence, primarily from $x$-ray absorption near-edge structure (XANES) spectroscopy, for the transient occurrence of a +2 oxidation state intermediate in the oxidation of $\mathrm{Ni}(\mathrm{II})$-catalyzed oxidation of aqueous sulfide. This technique (i) provides simultaneous qualitative and quantitative information on all the forms of sulfur present, (ii) does not require cumbersome preparation of the sample so greatly minimizing the problems of artifact formation and alteration in the samples' composition, and (iii) allows non-destructive analysis. We used Fourier-transform-infrared spectroscopy (FT-IR) to further characterize the intermediate. These spectroscopic measurements suggest that the +2 sulfur oxidation state intermediate has a sulfoxylate ion $\left(\mathrm{SO}_{2}{ }^{2-}\right)$ structure.

\section{Methods}

We conducted time-series experiments on sulfide oxidation using air-saturated solutions of $100 \mathrm{mM}$ anhydrous NaHS (Johnson Matthey Co., Ward Hill, MA) in deionized water at room temperature $\left(25 \pm 1^{\circ} \mathrm{C}\right)$. $\mathrm{Ni}(\mathrm{II})\left(\mathrm{NiCl}_{2}\right.$ at a concentration of $100 \mu \mathrm{M})$ was added to the solutions as this transition metal ion was shown to be an effective catalyst of sulfide oxidation (8). The $\mathrm{pH}$ ranged from 11.5-12.0. We did not adjust the $\mathrm{pH}$. with buffers because the IR absorption peaks of the compounds commonly used (for example, sodium tetraborate) might interfere with the peaks of sulfide oxidation intermediates. The sulfide solutions were prepared with nitrogensparged Milli-Q water, and were maintained in a nitrogen atmosphere. Samples for the oxidation-time series were prepared by passively exposing small volumes of the stock sulfide solution $(5-50 \mathrm{~mL})$ in air in relatively large volume flasks $(50-500$ $\mathrm{mL}$ ). Our previous observations suggest that with such high ratios of exposed area to volume, oxygen concentrations rapidly reach equilibrium with air through diffusion.

Sulfide and its oxidation products were determined using XANES spectroscopy at the National Synchrotron Light Source (NSLS) X-19A beam line, and 
FT-IR spectroscopy, based on the cylindrical internal reflection technique. For $x$-ray analysis, ca 1-2 mL of the samples were packaged in thin Mylar film bags (Chemplex Industries, Tuckahoe, NY). Sulfur standards were analyzed in the same way. The XANES data were collected as fluorescence excitation spectra, using a fluorescence detector placed at 90 degrees to the $x$-ray beam. Samples were run in a helium atmosphere to minimize the attenuation of the $x$-ray beam by air. The spectra were recorded so that the scanning procedure yielded sufficient pre-edge and post-edge data for precise determination of the background. The $\mathrm{x}$-ray energy was calibrated using XANES spectra of elemental sulfur measured between sample runs, assigning 2472.7 $\mathrm{eV}$ to the "white-line" maximum of elemental sulfur spectrum. A non-linear leastsquares fitting procedure, which uses linear combinations of normalized spectra of model compounds, gave quantitative information on the different forms of sulfur $(10,22)$. Further details of the XANES methodology were described elsewhere $(23)$.

The FT-IR spectra were recorded with a Nicolet 205 spectrometer fitted with a CIRCLE accessory (Spectra-Tech, Stamford, Connecticut) based on the cylindrical internal reflection technique for analyzing aqueous samples. The CIRCLE device was equipped with a $\mathrm{ZnSe}$ crystal with a frequency range of $20,000 \mathrm{~cm}^{-1}-650 \mathrm{~cm}^{-1}$.

\section{Results and Discussion}

A major reason for using XANES spectroscopy for sulfur speciation is that it provides an experimental approach to infer the charge density, and hence, the oxidation state of sulfur. As usually practiced, measuring the oxidation state is an empirical counting scheme; nevertheless, it is a simple, useful approach for expressing the relative electronic charge of an atom in a molecule without considering its electronic structure in detail. By definition; the oxidation state is a number which represents the charge that an atom would have if the electrons in a compound were assigned to the atoms in a certain way (15). Simply stated, this formal number reflects charges on atomic components assigned by regarding all compounds as totally ionic. In contrast to the traditional counting approach, calibration with edge energies from XANES spectroscopy is a direct experimental approach to determining the atomic charge density which can be correlated with the formal oxidation state (24).

Figure 1 shows the XANES spectra of the terminal oxidation state species $\mathrm{S}^{2-}$ and $\mathrm{SO}_{4}{ }^{2-}$, various intermediate oxidation state species (polysulfides, elemental sulfur, sulfite and thiosulfate), and an organic sulfoxide (dibenzyl sulfoxide). In the $x$-ray absorption spectrum, evidence for a change in atomic charge density is a shift in the position of the absorption edge, which corresponds to electronic transitions from 1 s to empty outer p orbitals for sulfur. Earlier, Kunzl suggested that there is a linear relationship between an edge shift and oxidation state based on his critical study on the shift of the K-absorption discontinuities of the oxides of several elements (25). As Figure 2 shows, a plot of edge energy vs. sulfur oxidation state gives a nearly linear correlation for most inorganic anions of sulfur. Thus, Kunzl's law provides a valuable way to determine the oxidation state of sulfur by XANES Spectroscopy. Ideally, Kunzl's law is valid for a monoatomic ionic species where the changes in its atomic charge density, represented by edge shifts, can be equated unambiguously to changes in its formal oxidation state (25). For atoms in polyatomic ions, and in 
molecules which are not fully ionic, deviations may occur because of significant covalent bonding, although other factors also may be involved. Thus, for organic sulfur compounds dominated by covalent bonding, XANES peak-energy correlation directly estimates the relative charge density of sulfur, although this may not correlate with the formal oxidation state derived empirically. However, as demonstrated in Figure 2, for oxoanions of sulfur (such as sulfate), there is a nearly linear relationship between edge energy and (formal) sulfur oxidation state, mainly because of the strong electron withdrawing capability of the number of oxygen atoms attached to the sulfur atom, which gives it a large positive charge. Thus, to a first-order approximation, the Kunzl's law can be applied for oxoanions of sulfur. In a recent study, this method was the basis for assigning new oxidation states for the two different sulfur atoms in thiosulfate $(-1$ and +5 for the terminal and inner sulfur atoms, respectively) (15).

Figure 3 shows the XANES spectra of $0.1 \mathrm{M}$ sulfide in deionized water, and in solution containing $\mathrm{Ni}(\mathrm{II})$, after different periods of exposure to air. In the spectra of the latter series, a striking feature is the presence of a peak at $2476.1 \mathrm{eV}$ during the initial period of oxidation (up to ca. 70 hours); the peak had completely disappeared after about 100 hours. We deconvoluted these spectra to obtain quantitative information on the oxidation products, using a non-linear least- squares fitting procedure. The spectra of samples were fitted with various linear combinations of the spectra of different sulfur standards, and the results of the best fit were taken to indicate the actual sulfur composition. For the deionized water series, and the $\mathrm{Ni}(\mathrm{II})$ series after about 100 hours of exposure to air (those spectra with no peak at $2476.1 \mathrm{eV}$ ), we could deconvolute the spectra fully with selected combinations from the spectra of hydrogen sulfide, sulfate, polysulfide, sulfite, and thiosulfate. However, spectra from the initial period of oxidation could not be fitted entirely with any combination of these standards, mainly due to this $2476.1 \mathrm{eV}$ peak. Therefore, we infer that this peak corresponds to a novel intermediate because none of the known intermediates have peaks at this position. In the plot of peak energy vs. oxidation state for various sulfur anions (Figure 2), this position corresponds to an oxidation state of +2 , indicating that the novel species contains a +2 oxidation state sulfur.

A +2 charge density for sulfur also is characteristic of organic sulfoxides, as shown experimentally with XANES edge-energy correlations (Figure 1). Here, the charge density of sulfur reflects mainly the effect of oxygen, as the carbon atoms attached to sulfur do not affect its charge density because both have similar electronwithdrawing capabilities. Thus, we could take advantage of the existence of organic sulfoxides with +2 charge density to quantitatively estimate the unknown intermediate. Figure 4 shows a typical analysis of an XANES spectrum, with benzyl sulfoxide as a surrogate for this unknown species, and Figure 5 gives an example of the time-dependence of the fraction of sulfur in various oxidation states. Thus, with $0.1 \mathrm{M}$ initial sulfide and $100 \mu \mathrm{M} \mathrm{NiCl}_{2}$, the +2 species reached a steady-state concentration of about $5 \mathrm{mM}$ ( $5 \%$ of the initial $\mathrm{H}_{2} \mathrm{~S}$ concentration) between 20 and $70 \mathrm{~h}$, but decreased thereafter as HS was depleted.

Further information about this intermediate was obtained using attenuated total reflectance FT-IR spectroscopy. For aqueous solutions, this technique is usable in 
the $750-1500$, and $1775-3700 \mathrm{~cm}^{-1}$ regions of the spectrum Initially, we obtained FT-IR spectra of aqueous solutions of the major oxoanions of sulfur to examine their IR absorption peaks due to sulfur - oxygen stretching modes. As shown in Figure 6 (A-D), their sulfur - oxygen stretching vibrations have large infrared extinction coefficients in the $800-1300 \mathrm{~cm}^{-1}$ range. The FT-IR spectra of aqueous sulfate and sulfite each show single symmetrical peaks with maxima at $1101.4 \mathrm{~cm}^{-1}$ and 935.5 $\mathrm{cm}^{-1}$, respectively. However, for the protonated oxoanions, $\mathrm{HSO}_{4}-$ and $\mathrm{HSO}_{3}^{-}$, the spectra assume a split, asymmetrical shape, reflecting suructural changes from symmetric to asymmetric (Figures $6 \mathrm{~A}$ and $6 \mathrm{~B}$ ). Thiosulfate exhibits two absorption peaks, a broad peak at $1118.8 \mathrm{~cm}^{-1}$ and a narrower one at $997.3 \mathrm{~cm}^{-1}$ (Figure $6 \mathrm{C}$ ). Aqueous polysulfides have no peaks in this region. Under conditions similar to those of the XANES experiments, the IR spectra of the oxidation-time series with added $\mathrm{Ni}(\mathrm{II})$ display three absorption peaks $\left(1116.9 \mathrm{~cm}^{-1}, 997.3 \mathrm{~cm}^{-1}, 918.2 \mathrm{~cm}^{-1}\right)$ in the $800-1300 \mathrm{~cm}^{-1}$ frequency region (6F). The peaks at $1116.9 \mathrm{~cm}^{-1}$ and $997.3 \mathrm{~cm}^{-1}$ clearly belong to thiosulfate, but that at $918.2 \mathrm{~cm}^{-1}$ cannot be attributed to either sulfite or sulfate. This peak exhibited a similar time behavior to that of the +2 XANES feature (Figure 7), strongly supporting our belief that this intermediate was the same as that identified by XANES spectroscopy. This unknown peak in the spectral region where the sulfur - oxygen stretching modes of aqueous-phase sulfur oxoanions, such as $\mathrm{SO}_{4}{ }^{2-}$ and $\mathrm{SO}_{3}{ }^{2-}$, also are present suggests that the new intermediate is an oxygenated sulfur species, either an oxoanion or an oxoacid. An oxoanion structure was more likely because of the basic $\mathrm{pH}$ (range $11.5-12.0$ ) of the sulfide solutions.

Based on relative charge density of +2 for sulfur calculated from the XANES results, we propose three structures for the oxoanion intermediate: sulfoxylate ion $\left(\mathrm{SO}_{2}{ }^{2-}\right)(\mathrm{I})$, bisulfoxylate ion $\left(\mathrm{HOSO}^{-}\right)(\mathrm{II})$, and sulfinate ion $\left(\mathrm{HS}(\mathrm{O}) \mathrm{O}^{-}\right)(\mathrm{II})$.

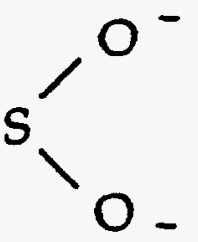

(I)

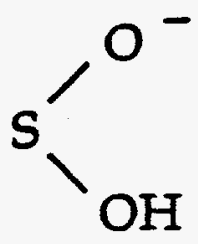

(II)

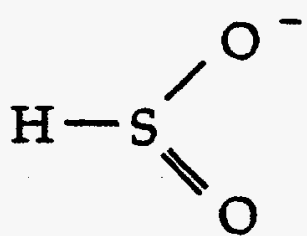

(III)

Although we cannot be as certain of its specific structure from XANES, the IR spectrum advantageously distinguishes among them. We obtained the IR spectrum characteristic of the intermediate by subtracting the thiosulfate spectrum from that of the sample (Figure 6E). The symmetrical shape of the spectrum suggests that the intermediate has a symmetrical structure, in analogy uith our observations for aqueous-phase sulfate and sulfite $(6 \mathrm{~B}, 6 \mathrm{D})$. Thus, the structure is likely to be $\mathrm{SO}_{2}{ }^{2-}$, and not $\mathrm{HOSO}^{-}$or $\mathrm{HS}(\mathrm{O}) \mathrm{O}^{-}$. Furthermore, if the structure has $\mathrm{HOSO}^{-}$, it would have produced a split, asymmetrical IR spectrum, analogous to those for aqueous-phase $\mathrm{HSO}_{4}^{-}$and $\mathrm{HSO}_{3}^{-}$ions $(6 \mathrm{~A})$. The $\mathrm{HS}(\mathrm{O}) \mathrm{O}^{-}$structure also would produce a asymmetrical IR spectrum because of its asymmetry. 
Both XANES and FT-IR spectroscopies suggest that the sulfoxylate ion is the initial intermediate formed in the $\mathrm{Ni}(\mathrm{II})$ catalyzed oxidation of aqueous sulfide. This is the lowest oxidation end member in the homologous series of sulfur oxoanions which include $\mathrm{SO}_{3}{ }^{2-}$ and $\mathrm{SO}_{4}{ }^{2-}$. Although the mechanisms which generate and stabilize the sulfoxylate intermediate are not well understood, our experiments suggest that strongly alkaline $\mathrm{pH}(11-12)$ is important in stabilizing it in aqueous solutions, and seems to facilitate its accumulation to significant levels during the initial period of oxidation. Upon acidification to 8.5, the IR absorption peak at 918.2 $\mathrm{cm}^{-1}$, corresponding to the sulfoxylate ion, disappeared immediately and completely; there was no indication of its conversion into the bisulfoxylate form (HOSO), analogous to the formation of bisulfate from sulfate (Figure 6A and 6B). However, at such a low pH, bisulfoxylate may be converted to other species as soon as it is formed.

In summary, our study provides direct experimental evidence for the existence of a +2 sulfur oxidation state oxoanion, the sulfoxylate ion, which was observed as a transient intermediate in the Ni(II) catalyzed oxidation of sulfide with molecular oxygen. In pure deionized water only, sulfoxylate may be formed at a slower rate, so that its concentration is below the detection limit of the XANES technique (about $0.5 \mathrm{mM}$ for most sulfur compounds at the X19A beamline). Although Hoffmann and Lim proposed that a similar species with $\mathrm{HSO}_{2}^{-}$stoichiometry was formed as the initial step in the oxidation of aqueous sulfide catalyzed by metal-phthalocyanine complexes $(7)$, such a species had not been detected. The role of this intermediate in forming other oxidation products is not understood; however, its observation is an important step forward in our understanding of the mechanism of sulfide oxidation.

\section{Acknowledgments}

This research was performed under the auspices of the U.S. Department of Energy Division of Engineering and Geosciences of the Office of the Basic Energy Sciences under Contract No. DE-AC02-76CH00016 (KC-04). We thank Mark Sweet for the use of Nicolet 205 FT-IR spectrometer. We acknowledge the valuable comments of Avril Woodhead and Stephen Schwartz (Brookhaven National Laboratory).

\section{Literature Cited}

1. Jorgensen, B.B. Nature 1982, 296, 643-645.

2. Orr, W. L. AAPG Bull. 1974, 58, 263-276.

3. Jørgensen, B. B.; Isaksen, M. F.; Jannasch, H. W. Science 1992, 258, 17561757.

4. Chen, K. Y.; Morris, J. C. Environ. Sci. Technol. 1972, 6, 529-537.

5. O'Brien, D. J.; Birkner, F. G. Environ. Sci. Technol. 1977, 11, 1114-1120.

6. Hoffmann, M. R. Environ. Sci. Technol. 1977, 11, 61-66.

7. Hoffmann, M. R.; Lim, B. C. Environ. Sci. Technol. 1979, 13, 1406-1414.

8. Weres, O.; Tsao, L.; Chatre, R. M. Corrosion-NACE 1985, 41, 307-316.

9. Zhang, J-Z.; Millero, F. Geochim. Cosmochim. Acti 1993, 57, 1705-1718. 
10. Vairavamurthy, A.; Manowitz, B.; Zhou, W.; Jeon, Y. In the Environmental Geochemistry of Sulfide Oxidation; Alpers, C. and Blowes, D. eds.; ACS Symposium Series, American Chemical Society, Washington D.C., 1994, pp 412-430.

11. Luther, G. W. II Geochim. Cosmochim. Acta 1991, 55, 2839-2849.,

12. Kohnen, M. E. L.; Sinninghe Damste, J. S.; ten Haven, H. L.; de Leeuw, J. W. Nature 1989, 341, 640-641.

13. Vairavamurthy, A.; Mopper, K. In Biogenic sulfur in the environment; Saltzman, E. S. and Cooper, W. J. eds.; ACS Symposium Series No. 393, ACS, Washington DC, 1989, pp 231-242.

14. Luther, G.W. III; Ferdelman, T.G. Environ. Sci. Technol. 1993, 27, 11541163.

15. Vairavamurthy, A; Manowitz, B; Luther, G. W. III; Jeon, Y. J. Geochim. Cosmochim. Acta, 1993, 57, 1619-1623.

16. Jacobs, L.; Emerson, S. Earth Planet. Sci. Lett. 1982, 60, 237-252.

17. Jørgensen, B. B.; Fossing, H.; Wirsen, C. O.; Jannasch, H. W. Deep-Sea Research 1991, 38, Suppl. 2, S1083-1103.

18. Plummer, P.L.; Chen, T.S.; Law, K. Y. Atm. Environ. 1984, 18, 27692774.

19. Laakso, D.; Marshall, P. J. Phys. Chem., 1992, 96, 2471-2474.

20. Steiger, T.; Steudel, R. J. Mol. Str., 1992, 257, 313-323.

21. Schmidt, M. In Sulfur in Organic and Inorganic Chemistry, Vol. 2; ed. Senning A.; Marcel Dekker, Inc., New York, 1972, pp 71-112.

22. Waldo, G.S.; Carlson, R.M.K.; Moldowan, J.M.; Peters, K.E.; PennerHahn, J.E. Geochim. Cosmochim. Acta 1991, 55, 801-814.

23. Vairavamurthy, A.; Zhou, W.; Eglinton, T.; Manoritz, B. Geochim. Cosmochim. Acta 1994, 21, 4681-4687.

24. Wong, J.; Lytle, F. W.; Messmer, R. P.; Maylotte, D. H. Physical Review 1984, B30, 5596-5607.

25. Kunzl, V. Collect. Czech. Commun. 1932, 4, 213-224. 


\section{Figure captions}

Figure 1. Normalized XANES spectra of the terminal oxidation state species $\mathrm{S}^{2-}$ and $\mathrm{SO}_{4}{ }^{2-} ;$ known $\mathrm{H}_{2} \mathrm{~S}$ oxidation intermediates, polysulfides, elemental sulfur, sulfite and thiosulfate, and dibenzyl sulfoxide with a charge density of +2 on sulfur.

Figure 2. Plot of XANES peak energy vs. sulfur oxidation state for $\mathrm{S}^{2-}$ (iron sulfide), $\mathrm{S}_{8}{ }^{0}, \mathrm{SO}_{3}{ }^{2-}, \mathrm{S}_{2} \mathrm{O}_{3}{ }^{2-}, \mathrm{SO}_{4}{ }^{2-}$ fitted with a linear least-squares line (correlation coefficient, $r=0.99$ ). The energy position (2476.1) of the unknown intermediate is shown by the filled circle on the regression line, and corresponds to +2 sulfur oxidation state.

Figure 3. Sulfur K-edge XANES spectra of oxidation-time series of $0.1 \mathrm{M}$ NaHS in deionized water at $25 \pm 1{ }^{\circ} \mathrm{C}$ : (A) pure deionized water, (B) with added $\mathrm{NiCl}_{2}(100$ $\mu \mathrm{M})$. The arrow indicates the XANES peak at $2476.1 \mathrm{eV}$ corresponding to the unknown species.

Figure 4. Non-linear least-squares fit of the XANES spectrum of $0.1 \mathrm{M}$ aqueous sulfide in deionized water with added $\mathrm{NiCl}_{2}(100 \mu \mathrm{M})$ after 63 hours of oxidation in air. Benzyl sulfoxide was used as a surrogate to quantify the unknown sulfide oxidation intermediate with a peak at $2476.1 \mathrm{eV}$.

Figure 5. Distribution of sulfur species during the oxidation of $0.1 \mathrm{M} \mathrm{NaHS}$ in water containing $\mathrm{NiCl}_{2}(100 \mu \mathrm{M})$.

Figure 6. A-D, Fourier-transform infrared spectra of aqueous sulfur standards; F, spectra of oxidation-time series of aqueous NaHS $(0.2 \mathrm{M})$ with added $\mathrm{NiCl}_{2}(100$ $\mu \mathrm{M})$ at $25 \pm 1{ }^{\circ} \mathrm{C}$. The spectrum of the sulfoxylate ion (E) was obtained by subtracting the thiosulfate spectrum from that of the sample corresponding to 23.5 $\mathrm{h}$ oxidation.

Figure 7. Distribution of thiosulfate and sulfoxylate from the IR data of the oxidation-time series shown in Figure 6F. Thiosulfate was calibrated using the broad peak in the spectrum. Sulfoxylate ion concentrations were estimated using the same thiosulfate calibration. 


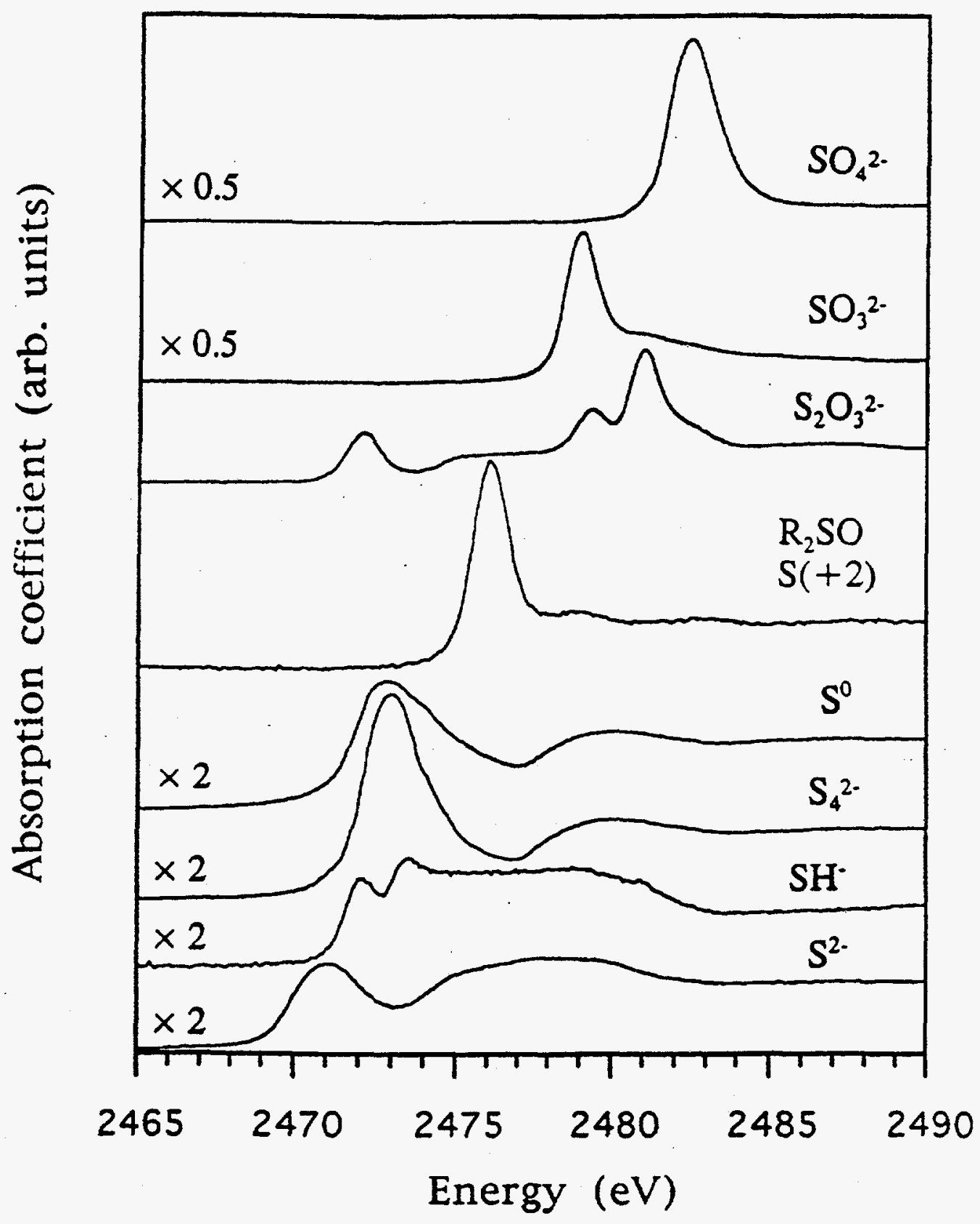

Figure 1 


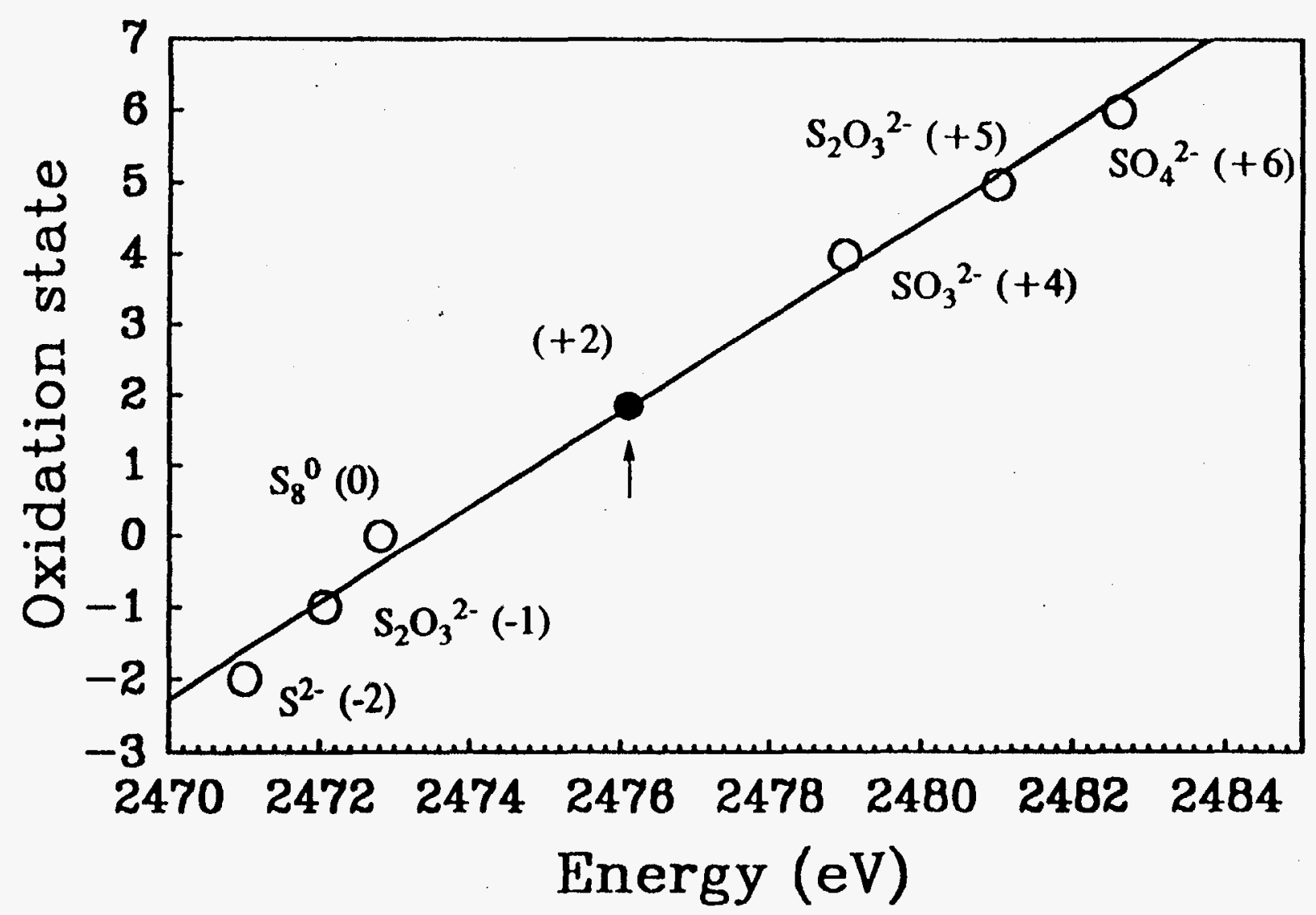




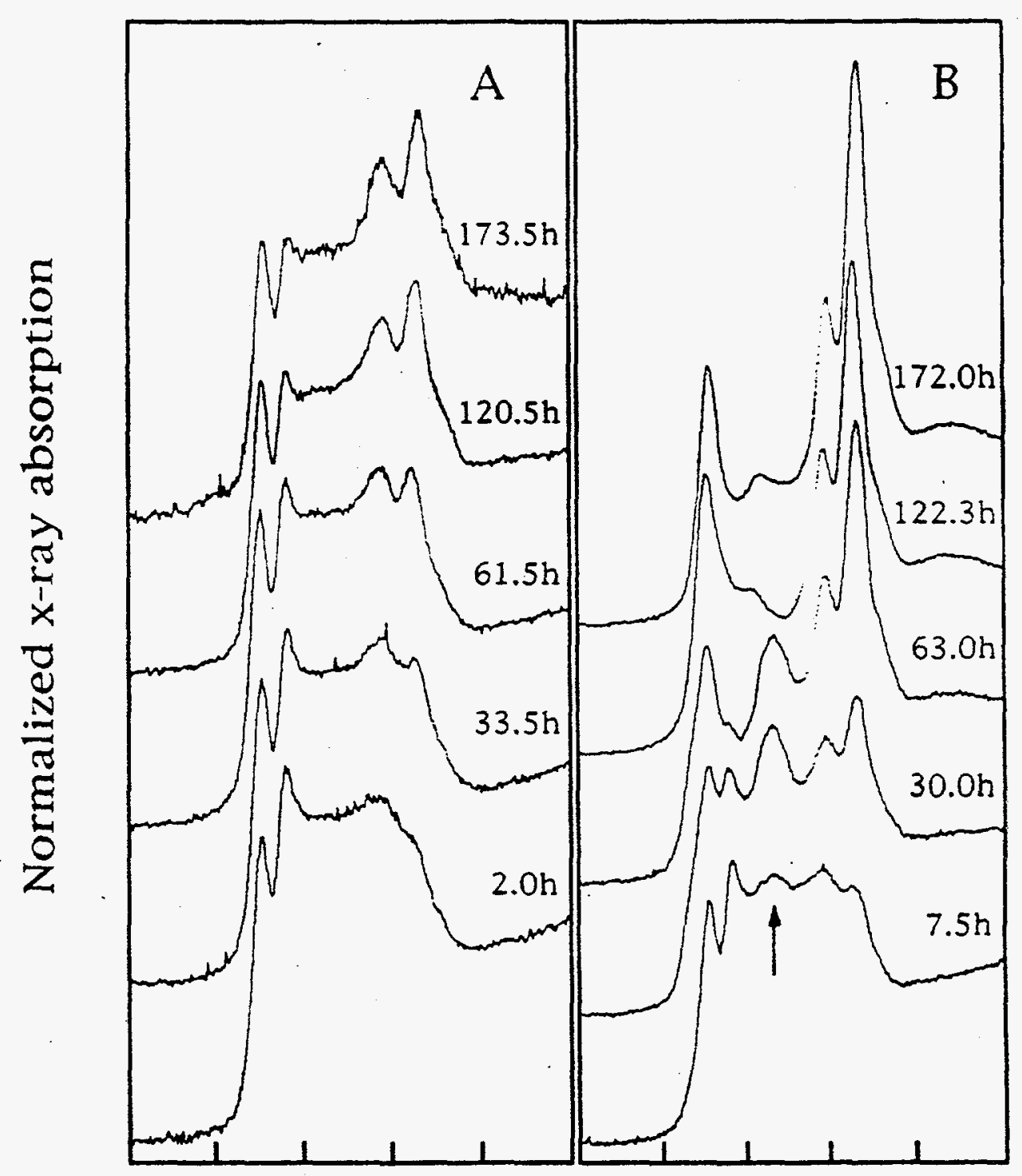

$24652470247524802485 \quad 246524702475248024852490$

Energy $(\mathrm{eV})$

Figure 3 


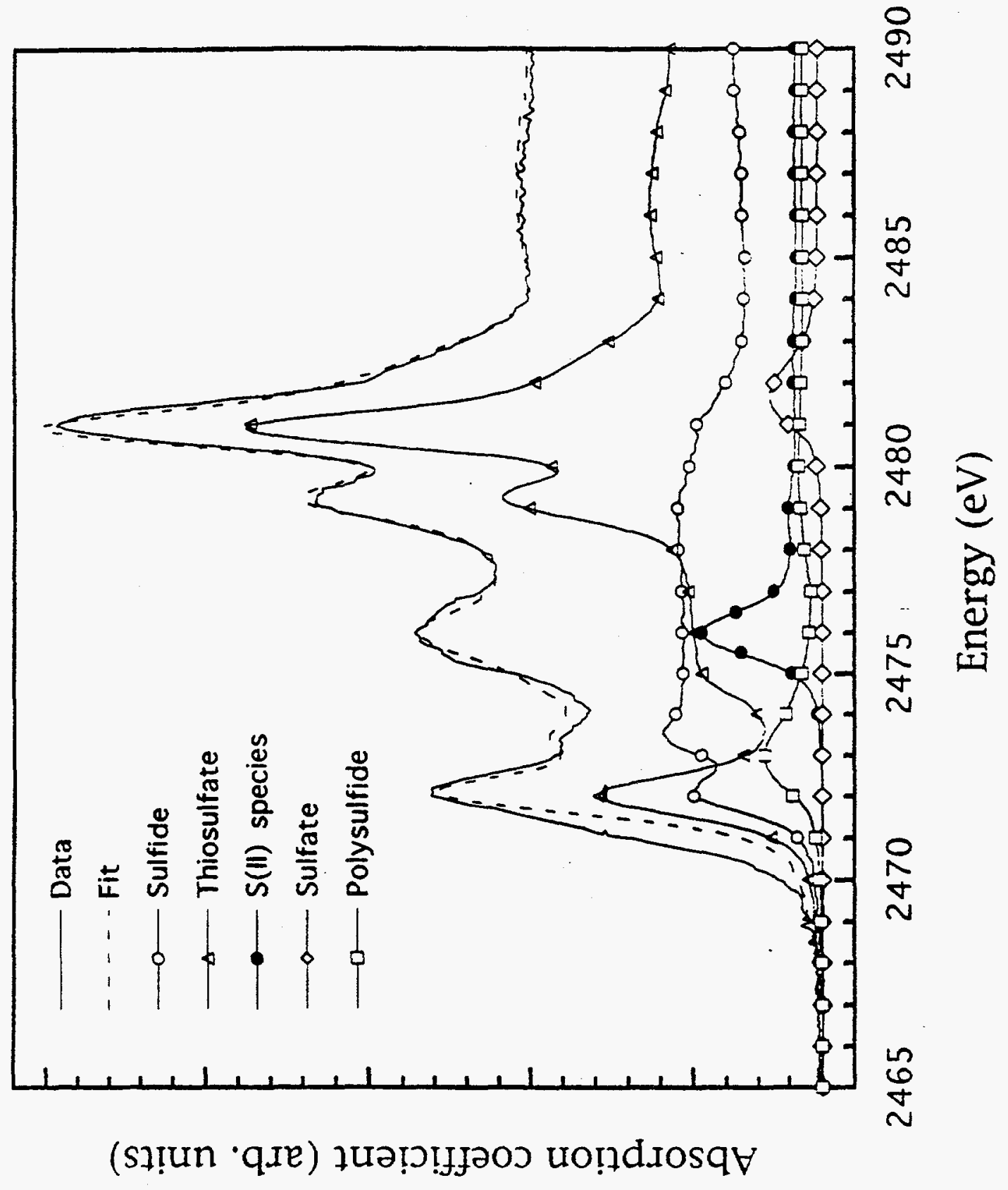

Figure 4 


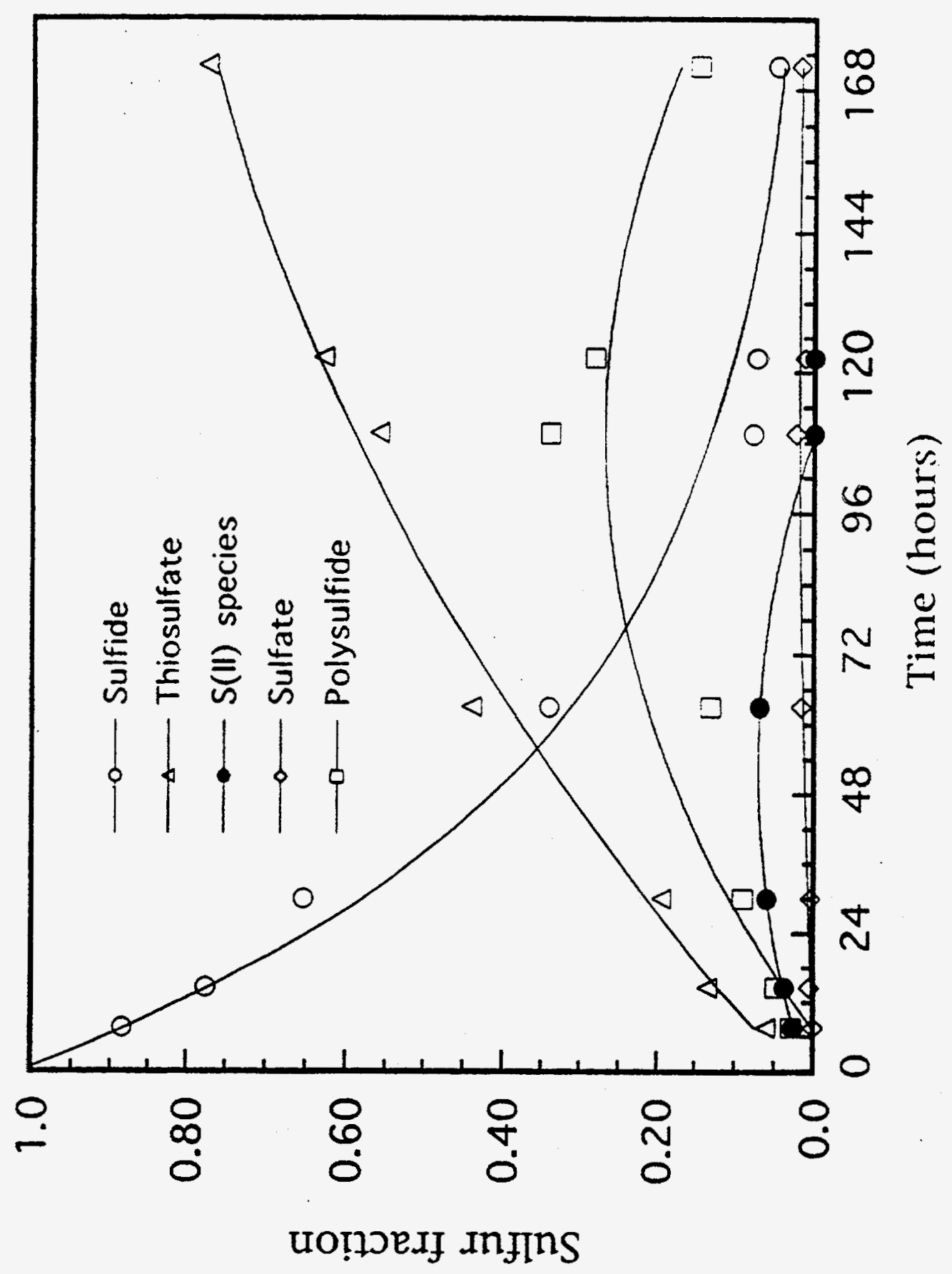

Figure 5 


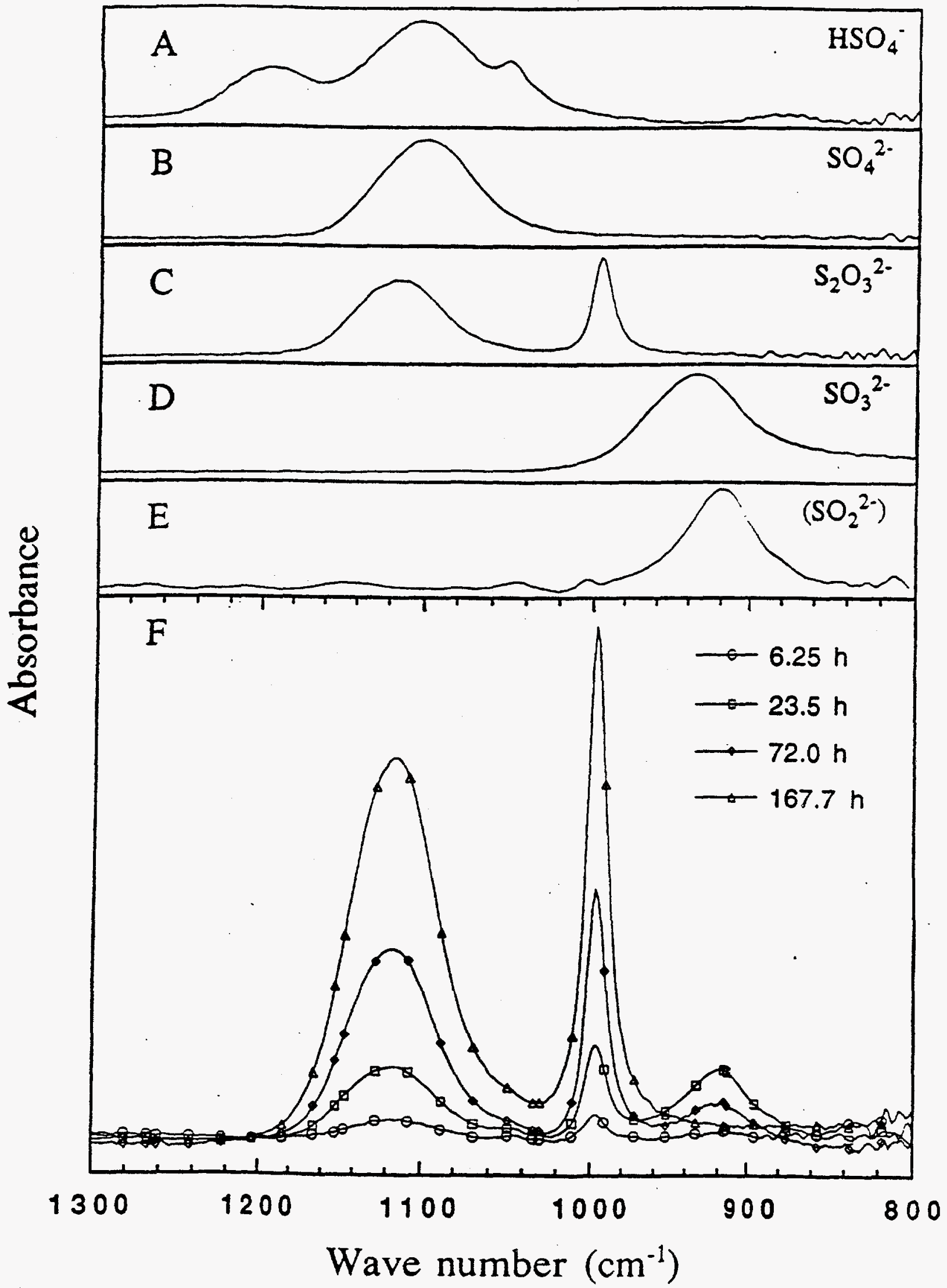

Figure 6 


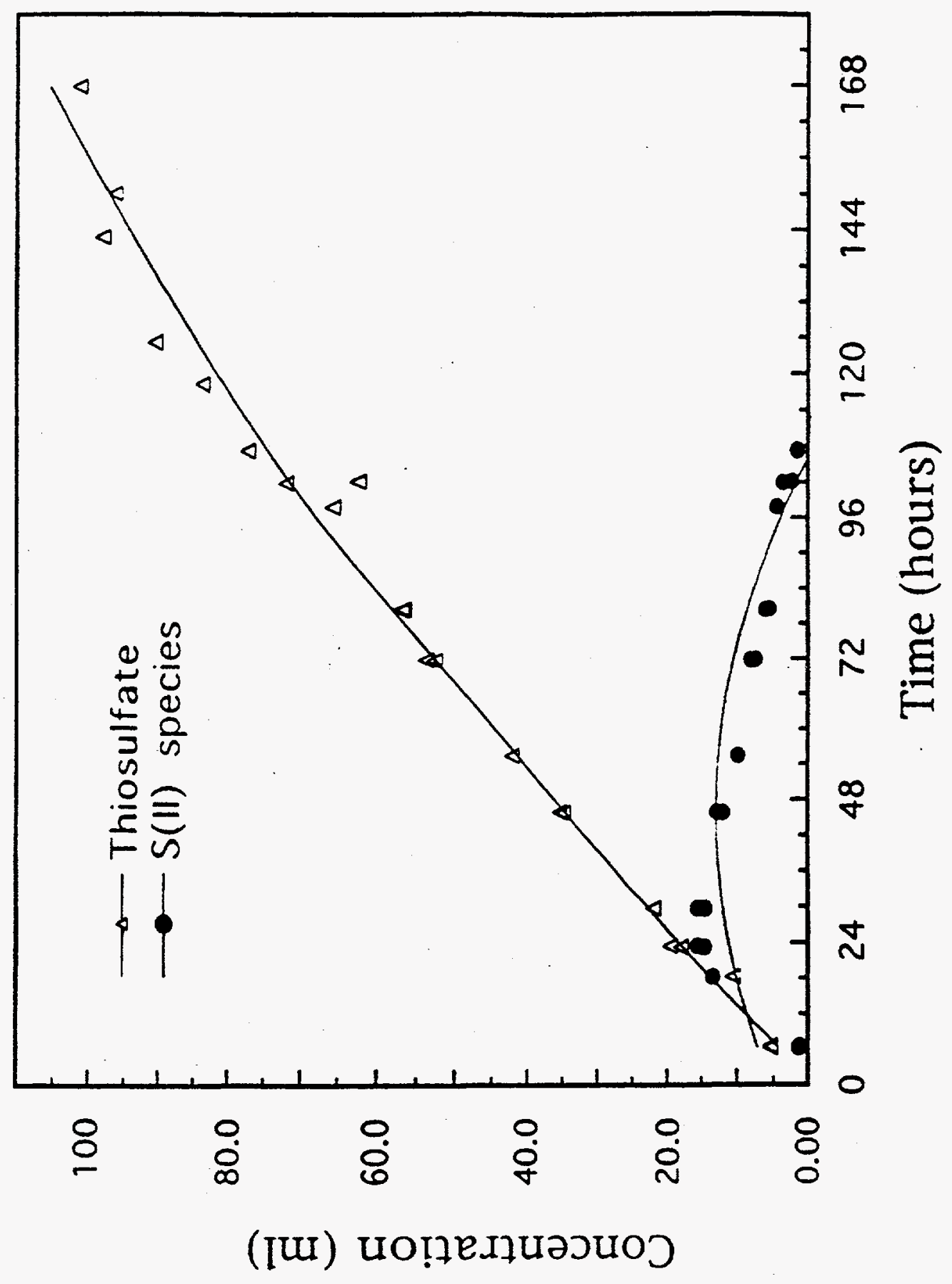

Figure 7 